\title{
Dose-volume analysis of target volume and critical structures in computed tomography image-based multicatheter high-dose-rate interstitial brachytherapy for head and neck cancer
}

\author{
Hironori Akiyama, DDS, PhD',2, Tibor Major, PhD!, Csaba Polgár, MD, PhD', Zoltán Takácsi-Nagy, MD, PhD' \\ 'Center of Radiotherapy, National Institute of Oncology, Budapest, Hungary. ${ }^{2}$ Department of Oral Radiology. Osaka Dental University. \\ Osaka, Japan
}

\begin{abstract}
Purpose: To evaluate dose-volume relationships of target volume and critical structures in computed tomography (CT) image-based brachytherapy for head and neck cancer.

Material and methods: Thirty-seven patients with mobile tongue, floor of mouth, and base of tongue cancer treated with brachytherapy (post-operative alone and as a boost after external beam radiotherapy [EBRT], or definitive alone or as a boost after EBRT) were selected. Treatment plans were made using post-implant CT images. The fractionation schedule was 7-15 × 3-5 Gy for post-operative (with or without EBRT), 14-15 × 3 Gy for definitive alone, and 5-10 × 3 Gy for boost treatments. For the target volume, $\mathrm{V}_{100}, \mathrm{D}_{90}$, and dose non-uniformity ratio (DNR) were calculated. For the mandible, spinal cord and salivary glands doses to specified volumes were reported.

Results: The median values of $\mathrm{V}_{100}$ and $\mathrm{D}_{90}$ were $89.9 \%$ and $99.9 \%$, respectively; the median values of DNR was 0.46 . The median $\mathrm{D}_{2 \mathrm{~cm}^{3}}$ of the mandible and spinal cord were $48.3 \%$ and $5.8 \%$, respectively. The ipsilateral median $\mathrm{D}_{2 \mathrm{~cm}^{3}}$ of parotid and submandibular glands were $6.4 \%$ and $12.5 \%$, whereas on the contralateral side, the corresponding values were $5.3 \%$ and $7.0 \%$, respectively.

Conclusions: Using conformal treatment planning, it was desirable to keep the dose to the mandible, spinal cord, and salivary glands at an acceptable level. The quantitative plan evaluation may help us find correlations between dosimetric parameters and clinical outcome, which may lead to improve the quality of the treatment, but it requires longer follow-up and results from other studies.
\end{abstract}

Key words: brachytherapy, CT, dosimetry, head and neck, HDR.

\section{Purpose}

The goal of any technology developed for radiation therapy is to deliver lethal doses to the target volume defined by radiation oncologists, while keeping doses to adjacent normal tissue as low as possible. Advancements in brachytherapy (BT) have been characterized by delivering a total dose, which cannot be safely given by external beam radiotherapy (EBRT) alone, and the rapid dose fall-off that allows relative sparing of critical and normal tissues [1]. In this respect, BT alone or as a boost is used for the management of malignancies in head and neck, gynecological, and other regions [2,3]. Especially for head and neck malignancies, BT is difficult because this region has complex anatomical structures with functional and cosmetic importance. Low-dose-rate (LDR) BT for head and neck malignancies has long been in use, and it is an established method. However, it has some shortcomings, such as radiation exposure to medical staff, isolation of patients for a long time in a shielded room with limited time of nursing care due to radiation exposure, and without dose optimization after implantation. Remote after-loading high-dose-rate (HDR) stepping source system has been introduced to eliminate some defects of LDR BT $[4,5]$.

Recently, with the development of imaging modalities, such as computed tomography (CT), magnetic resonance imaging (MRI), and ultrasonography, image-based HDR BT has been implemented. Using three-dimensional (3D) cross-sectional image sets, radiation oncologists and medical physicists can depict the target volume and critical structures, and calculate the volumetric doses delivered 
to these organs $[5,6,7,8,9,10,11,12]$. In the gynecological region, there are recommendations about image-based BT, where authors referring to concepts and terms in 3D image-based treatment planning, 3D dose volume parameters, aspects of 3D image-based anatomy, radiation physics and radiobiology $[13,14]$. However, as to the head and neck region, the recommendations of the Groupe Européen de Curiethérapie-European Society for Therapeutic Radiology and Oncology (GEC-ESTRO) define that it is too early for precise suggestion regarding the use of 3D imaging and optimization in BT of head and neck tumors [1] and in its $1^{\text {st }}$ update, the authors reported that standardized organ at risk dose-volume constraints in head and neck BT are lacking [15]. In this study, we present the dosimetric data of 3D image-based HDR BT in patients with head and neck cancers by applying dosevolume analysis of the target volume and critical structures. The dosimetry of BT with EBRT was not compared.

\section{Material and methods}

\section{Patients' characteristics}

Between January 2013 and January 2017, thirty-seven patients with mobile tongue $(n=15$, left side: right side $=$ $12: 3$, T1 : T2: T3: T4 $=6: 5: 2: 2)$, floor of mouth $(n=9$, left side: right side: middle $=3: 3: 3, \mathrm{~T} 1: \mathrm{T} 2=8: 1)$, and base of tongue $(n=13$, left side: right side $=3: 10 ; \mathrm{T} 1: \mathrm{T} 2: \mathrm{T} 3$ : $\mathrm{T} 4=3: 3: 4: 3$ ) cancer treated with multicatheter HDR BT were selected for this study at our institute (post-operative \pm EBRT, $n=14$, or definitive alone, $n=3$, or as a boost after EBRT, $n=20)$. The mean follow-up period was 24 months (range, 3-53 months) (Table 1).

\section{Implantation and treatment planning}

Plastic catheters (Elekta, Brachytherapy, Veenendaal, The Netherlands) (median 7, range 3-12) were implanted into the region of the target volume in surgical act under visual guidance. After catheter implantation, all patients underwent CT imaging. The images were transferred to Oncentra Brachy v. 4.3 (Elekta, Brachytherapy, Veenendaal, The Netherlands) planning system, which uses the TG-43 calculation formalism without taking into consideration the tissue heterogeneities. Based on CT

Table 1. Treatment characteristics

\begin{tabular}{lcc}
\hline Factor & $n$ & Fractionation schedule \\
\hline Postoperative w/o EBRT & 14 & $\begin{array}{c}7-15 \times 3-5 \text { Gy } \\
\text { (total dose of 21-48 Gy) }\end{array}$ \\
\hline Definitive alone & 3 & $\begin{array}{c}14-15 \times 3 \text { Gy } \\
\text { (total dose of 42-45 Gy) }\end{array}$ \\
\hline Boost after EBRT & 20 & $\begin{array}{c}5-10 \times 3 \text { Gy } \\
\text { (total dose of 15-30 Gy) }\end{array}$ \\
\hline \begin{tabular}{l} 
Implant location \\
\hline Left side
\end{tabular} & 18 & \\
\hline Right side & 16 & \\
\hline Middle & 3 &
\end{tabular}

$n$-number of patients for analysis, w/o - with or without, EBRT - external beam radiotherapy image sets, the planning target volume (PTV) and critical structures as the mandible, spinal cord, and salivary glands (parotid and submandibular glands) on both sides were delineated by the same person (HA). Because tumor or tumor bed were sometimes not visible on CT images, positions of the inserted catheters, inspection, palpation, and MR images could help in determination of the PTV contour. After catheter reconstruction, treatment plans were made with geometrical optimization. Then, we adjusted the isodose curve with graphical optimization in order to cover the PTV appropriately by the prescribed dose (PD), and maintain the doses to critical structures as low as possible. Dose non-uniformity ratio (DNR) was defined as the ratio of volume receiving 1.5 times of the $\mathrm{PD}$ and the PD $\left(\mathrm{V}_{150} / \mathrm{V}_{100}\right)$. Our aim was to gain DNR $\leq 0.40$ [16]. The fractionation schedule was 7-15 x 3-5 Gy (total dose of 21-48 Gy) for post-operative, 14-15 x $3 \mathrm{~Gy}$ (total dose of 42-45 Gy) for definitive alone, and 5-10 x 3 Gy (total dose of 15-30 Gy) for boost treatments [1].

\section{Target volume evaluation}

For quantitative estimation of doses for the target volume coverage, the following dose-volume parameters were calculated using dose-volume histograms (DVH): percentage volume of the PTV receiving more than $100 \%$ and $150 \%$ of the PD $\left(\mathrm{V}_{100}\right.$ and $\left.\mathrm{V}_{150}\right)$; minimum percentage dose of the PD that was given to $90 \%$ and $100 \%$ of the PTV $\left(\mathrm{D}_{90}\right.$ and $\left.\mathrm{D}_{100}\right)$. To analyze homogeneity and conformity of dose distributions, we calculated dose non-uniformity ratio (DNR), dose homogeneity index (DHI), and conformal index (COIN). Their definitions were as follows: $\mathrm{DNR}=\mathrm{V}_{150} / \mathrm{V}_{100} ; \mathrm{DHI}=\left(\mathrm{V}_{100}-\mathrm{V}_{150}\right) / \mathrm{V}_{100}$; $\mathrm{COIN}=\left(\mathrm{PTV}_{100} / \mathrm{V}_{\mathrm{PTV}}\right) \times\left(\mathrm{PTV}_{100} / \mathrm{V}_{100}\right)$.

The PTV 100 and $V_{\text {PTV }}$ are indicated as absolute partial volume of the PTV, receiving $100 \%$ of the PD and absolute volume of the PTV, respectively.

\section{Critical structures evaluation}

As critical structures, we selected the mandible, spinal cord, and salivary glands (parotid and submandibular glands) on both sides. For the mandible and spinal cord, minimum percentage doses of the PD that was given to maximally irradiated $0.1 \mathrm{~cm}^{3}, 1 \mathrm{~cm}^{3}$, and $2 \mathrm{~cm}^{3}$ volumes $\left(D_{0.1 \mathrm{~cm}^{3}}, \mathrm{D}_{1 \mathrm{~cm}}{ }^{3}\right.$, and $\left.\mathrm{D}_{2 \mathrm{~cm}}\right)$ were calculated from $\mathrm{DVH}$. Salivary glands were divided into two groups: ipsilateral and contralateral, based on the implant location. Three patients had centrally located tumor and were excluded from salivary gland analysis. The following dose-volume parameters of each group such as ipsilateral and contralateral side were calculated using DVH: mean dose in percentage of the PD $\left(\mathrm{D}_{\text {mean }}\right)$, percentage volume of each salivary gland receiving more than $10 \%, 30 \%$, and $50 \%$ of the PD $\left(\mathrm{V}_{10}, \mathrm{~V}_{30}\right.$, and $\left.\mathrm{V}_{50}\right)$, and minimum percentage dose of the PD that was given to $10 \%, 30 \%$, and $50 \%$ of each salivary gland $\left(D_{10}, D_{30}\right.$, and $\left.D_{50}\right)$ fully detected with CT images (some salivary glands were not adequately represented on the CT because of having been removed by operation, atrophy by EBRT, and patients' position during (T), minimum percentage dose of the PD that was given to maximally irradiated $0.1 \mathrm{~cm}^{3}, 1 \mathrm{~cm}^{3}$, and $2 \mathrm{~cm}^{3}$ 
Table 2. Evaluation of implant-related dosimetric parameters

\begin{tabular}{|c|c|c|c|c|c|c|c|}
\hline \multirow[t]{2}{*}{ Parameters } & \multicolumn{2}{|c|}{ All, $n=37$} & \multicolumn{2}{|c|}{$\begin{array}{c}\text { Mobile tongue, } \\
\text { floor of mouth, } n=24\end{array}$} & \multicolumn{2}{|c|}{$\begin{array}{l}\text { Base of tongue, } \\
\qquad n=13\end{array}$} & \multirow[t]{2}{*}{$p$ value } \\
\hline & Median & Range & Median & Range & Median & Range & \\
\hline$V_{100}\left(\mathrm{~cm}^{3}\right)$ & 16.8 & $6.5-43.8$ & 16.0 & $6.5-43.8$ & 18.0 & 9.9-32.9 & $>0.05$ \\
\hline$V_{150}\left(\mathrm{~cm}^{3}\right)$ & 7.0 & $2.9-21.0$ & 6.6 & $2.9-21.0$ & 7.6 & $4.3-15.6$ & $>0.05$ \\
\hline DNR & 0.46 & $0.34-0.58$ & 0.45 & $0.34-0.57$ & 0.47 & $0.36-0.58$ & $>0.05$ \\
\hline
\end{tabular}

$n$-number of patients for analysis, $V_{100}, V_{150}$-volume receiving $100 \%$ and $150 \%$ or more of the prescribed dose, DNR - dose nonuniformity ratio

Table 3. Evaluation of the PTV-related parameters

\begin{tabular}{|c|c|c|c|c|c|c|c|}
\hline \multirow[t]{2}{*}{ Parameters } & \multicolumn{2}{|c|}{ All, $n=37$} & \multicolumn{2}{|c|}{$\begin{array}{c}\text { Mobile tongue, } \\
\text { floor of mouth, } n=24\end{array}$} & \multicolumn{2}{|c|}{$\begin{array}{l}\text { Base of tongue, } \\
\quad n=13\end{array}$} & \multirow[t]{2}{*}{$p$ value } \\
\hline & Median & Range & Median & Range & Median & Range & \\
\hline$V_{\text {PTV }}\left(\mathrm{cm}^{3}\right)$ & 12.9 & $5.2-42.3$ & 12.7 & $5.2-42.3$ & 13.7 & $6.9-35.0$ & $>0.05$ \\
\hline $\mathrm{PTV}_{100}\left(\mathrm{~cm}^{3}\right)$ & 11.2 & 4.6-32.9 & 11.1 & 4.6-32.9 & 12.4 & $6.2-29.4$ & $>0.05$ \\
\hline \multicolumn{8}{|l|}{ Coverage (\%) } \\
\hline$V_{100}$ & 89.9 & 77.8-93.5 & 90.0 & 77.8-93.5 & 90.0 & 79.9-90.9 & $>0.05$ \\
\hline$V_{150}$ & 44.1 & 36.3-63.6 & 43.9 & $36.3-54.3$ & 45.5 & $37.6-63.6$ & $>0.05$ \\
\hline $\mathrm{D}_{90}$ & 99.9 & $83.4-105.2$ & 99.9 & 83.4-105.2 & 100.0 & $87.2-101.1$ & $>0.05$ \\
\hline$D_{100}$ & 57.0 & $37.6-73.4$ & 57.9 & $37.6-73.4$ & 56.9 & $48.0-68.6$ & $>0.05$ \\
\hline \multicolumn{8}{|l|}{ Homogeneity } \\
\hline $\mathrm{DHI}$ & 0.50 & $0.29-0.61$ & 0.50 & $0.37-0.61$ & 0.48 & $0.29-0.59$ & $>0.05$ \\
\hline \multicolumn{8}{|l|}{ Conformity } \\
\hline COIN & 0.64 & $0.51-0.77$ & 0.64 & $0.58-0.77$ & 0.66 & $0.51-0.75$ & $>0.05$ \\
\hline
\end{tabular}

$n$ - number of patients for analysis, PTV - planning target volume, PD - prescribed dose, VPTV - volume of the PTV, PTV $100-$ partial volume of the PTV receiving the $P D, V_{100}, V_{150}$ - percentage volume of the PTV receiving $100 \%$ and $150 \%$ or more of the $P D, D_{90}, D_{100}$ - minimum percentage dose of the PD that was given to $90 \%$ and $100 \%$ of the PTV, DHI-dose homogeneity index, COIN - conformal index

volumes of each salivary gland $\left(\mathrm{D}_{0.1 \mathrm{~cm}^{3}}, \mathrm{D}_{1 \mathrm{~cm}^{3}}\right.$, and $\left.\mathrm{D}_{2 \mathrm{~cm}^{3}}\right)$. In those cases, where the full volume of parotid glands was not visible on the $\mathrm{CT}$, only $\mathrm{D}_{0.1 \mathrm{~cm}^{3}}, \mathrm{D}_{1 \mathrm{~cm}}{ }^{3}$, and $\mathrm{D}_{2 \mathrm{~cm}^{3}}$ parameters were calculated.

\section{Statistical analysis}

We presented the results as the median and ranges according to each subdivided site such as mobile tongue (including floor of mouth) and base of tongue. We compared these parameters by using non-parametric Mann-Whitney $U$ test. To examine the relationships of $V_{100}$ and $D_{90}, V_{\text {PTV }}$ and $V_{100}, D_{2 \mathrm{~cm}^{3}}$ and $D_{1 \mathrm{~cm}^{3}}$, and $D_{1 \mathrm{~cm}^{3}}$ and $D_{0.1 \mathrm{~cm}^{3}}$, linear regression analysis was performed. We considered the level of statistical significance as $p \leq 0.05$. For statistical analysis we used GraphPad Prism version 5.01 for Windows (GraphPad Software, San Diego, CA, USA).

\section{Results}

Generally, mobile tongue and floor of mouth cancer patients were operated, and then received HDR BT in case of positive or close margin. A few patients were treated with HDR BT alone without surgery. Base of tongue cancer patients received EBRT followed by HDR BT with or without operation. During the follow-up period, 15 patients had local and/or regional relapse and
24 patients were alive. One patient had soft tissue necrosis as a late adverse events.

Tables 2-7 shows parameters analyzed in this study. The respective values are given below.

\section{Dosimetric evaluation of implant}

The characteristics of implant related dosimetric parameters are shown in Table 2 . The median volume receiving $100 \%$ or more of the PD $\left(\mathrm{V}_{100}\right)$ for all primary sites was $16.8 \mathrm{~cm}^{3}$ (range, $6.5-43.8 \mathrm{~cm}^{3}$ ). The DNR slightly surpassed 0.40 , with the median of 0.46 (range, $0.34-0.58$ ) for all primary sites. There were no significant differences in the parameters between mobile tongue (including floor of mouth) and base of tongue tumors.

\section{Dosimetric evaluation of the PTV}

The characteristics of the PTV related parameters are illustrated in Table 3. For all primary sites, the median $\mathrm{V}_{\text {PTV }}$ was $12.9 \mathrm{~cm}^{3}$ (range, $5.2-42.3 \mathrm{~cm}^{3}$ ). The median dose coverage of the PTV was characterized with $\mathrm{V}_{100}$ of $89.9 \%$ (range, $77.8-93.5 \%$ ), $\mathrm{V}_{150}$ of $44.1 \%$ (range, $36.3-63.6 \%$ ), $\mathrm{D}_{90}$ of $99.9 \%$ (range, $83.4-105.2 \%$ ), and $\mathrm{D}_{100}$ of $57.0 \%$ (range, $37.6-73.4 \%)$, respectively. The median DHI and COIN were 0.50 (range, 0.29-0.61) and 0.64 (range, 0.51-0.77). There were no significant differences in the parameters 
Table 4. Evaluation of the mandible- and spinal cord-related parameters

\begin{tabular}{|c|c|c|c|c|c|c|c|c|c|c|}
\hline \multirow[t]{2}{*}{ Parameters } & \multicolumn{3}{|c|}{ All } & \multicolumn{3}{|c|}{ Mobile tongue, floor of mouth } & \multicolumn{3}{|c|}{ Base of tongue } & \multirow[t]{2}{*}{$p$ value } \\
\hline & $n$ & Median & Range & $n$ & Median & Range & $n^{*}$ & Median & Range & \\
\hline \multicolumn{11}{|l|}{ Mandible } \\
\hline $\mathrm{D}_{0.1 \mathrm{~cm}^{3}}(\%)$ & 37 & 81.8 & 25.1-134.1 & 24 & 84.1 & 61.2-134.1 & 13 & 66.2 & 25.1-101.5 & $<0.05$ \\
\hline $\mathrm{D}_{1 \mathrm{~cm} \mathrm{~m}^{3}}(\%)$ & 37 & 57.8 & 19.6-81.6 & 24 & 58.6 & $46.4-81.6$ & 13 & 44.2 & $19.6-65.2$ & $<0.05$ \\
\hline $\mathrm{D}_{2 \mathrm{~cm}} \mathrm{~cm}^{3} \%$ & 37 & 48.3 & $17.5-73.2$ & 24 & 50.3 & 38.3-73.2 & 13 & 36.2 & $17.5-55.9$ & $<0.05$ \\
\hline \multicolumn{11}{|l|}{ Spinal cord } \\
\hline $\mathrm{D}_{0.1 \mathrm{~cm}^{3}}(\%)$ & 36 & 10.0 & $4.9-15.4$ & 24 & 9.6 & $4.9-13.3$ & 12 & 11.3 & $8-15.4$ & $<0.05$ \\
\hline $\mathrm{D}_{1 \mathrm{~cm} \mathrm{~m}^{3}}(\%)$ & 36 & 6.8 & 3.3-11.8 & 24 & 6.0 & 3.3-9.8 & 12 & 7.8 & 4.9-11.8 & $<0.05$ \\
\hline$D_{2 \mathrm{~cm}^{3}}(\%)$ & 36 & 5.8 & $2.8-10.8$ & 24 & 5.3 & $2.8-8.9$ & 12 & 7.0 & $3.8-10.8$ & $<0.05$ \\
\hline
\end{tabular}

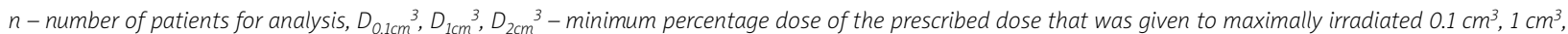
$2 \mathrm{~cm}^{3}$ volume of the organs, ${ }^{*}$ - in one patient spinal cord was not detected on planning CT images because it was out of field of view

Table 5. Evaluation of ipsilateral salivary glands-related parameters

\begin{tabular}{|c|c|c|c|c|c|c|c|c|c|c|}
\hline \multirow[t]{2}{*}{ Parameters } & \multicolumn{3}{|c|}{ All } & \multicolumn{3}{|c|}{$\begin{array}{l}\text { Mobile tongue, } \\
\text { floor of mouth }\end{array}$} & \multicolumn{3}{|c|}{ Base of tongue } & \multirow[t]{2}{*}{$p$ value } \\
\hline & $n$ & Median & Range & $n$ & Median & Range & $n$ & Median & Range & \\
\hline \multicolumn{11}{|l|}{ Parotid gland } \\
\hline $\mathrm{D}_{\text {mean }}(\%)$ & 15 & 4.1 & $2.0-6.5$ & 12 & 3.7 & $2.0-6.1$ & 3 & 5.8 & $4.1-6.5$ & $>0.05$ \\
\hline $\mathrm{D}_{0.1 \mathrm{~cm}^{3}}(\%)$ & 33 & 10.8 & 5.9-17.1 & 20 & 10.8 & 5.9-14.0 & 13 & 11.4 & 9.7-17.1 & $>0.05$ \\
\hline $\mathrm{D}_{1 \mathrm{~cm}} \mathrm{~cm}^{3}(\%)$ & 33 & 7.5 & 4.2-13.4 & 20 & 7.5 & 4.3-10.1 & 13 & 7.7 & $6.2-13.3$ & $>0.05$ \\
\hline $\mathrm{D}_{2 \mathrm{~cm}}{ }^{3}(\%)$ & 33 & 6.4 & 3.8-11.8 & 20 & 6.3 & $3.8-9.4$ & 13 & 6.5 & 4.6-11.8 & $>0.05$ \\
\hline $\mathrm{D}_{10}(\%)$ & 15 & 6.7 & $3.5-99$ & 12 & 6.3 & $3.5-9.1$ & 3 & 8.8 & $6.7-9.9$ & $>0.05$ \\
\hline$D_{30}(\%)$ & 15 & 5.1 & $2.6-7.6$ & 12 & 4.8 & 2.6-7.1 & 3 & 6.9 & $5.1-7.6$ & $>0.05$ \\
\hline$D_{50}(\%)$ & 15 & 4.1 & $2.0-6.3$ & 12 & 3.7 & $2.0-5.9$ & 3 & 5.6 & $4.1-6.3$ & $>0.05$ \\
\hline $\mathrm{V}_{10}(\%)$ & 15 & 0.8 & $0.0-9.1$ & 12 & 0.7 & $0.0-5.0$ & 3 & 3.7 & 0.8-9.1 & $>0.05$ \\
\hline \multicolumn{11}{|c|}{ Submandibular gland } \\
\hline$\underline{D}_{\text {mean }}(\%)$ & 22 & 12.3 & $5.9-41.8$ & 13 & 9.4 & $6.0-28.0$ & 9 & 21.0 & $5.9-41.8$ & $<0.05$ \\
\hline $\mathrm{D}_{0.1 \mathrm{~cm}^{3}}(\%)$ & 22 & 20.6 & $11.4-62.5$ & 13 & 19.7 & $11.8-43.5$ & 9 & 32.7 & $11.4-62.5$ & $>0.05$ \\
\hline $\mathrm{D}_{1 \mathrm{~cm}^{3}}(\%)$ & 20 & 15.1 & $7.7-42.2$ & 13 & 13.5 & $9.6-34.3$ & 7 & 25.7 & $7.7-42.2$ & $>0.05$ \\
\hline $\mathrm{D}_{2 \mathrm{~cm}} \mathrm{~cm}^{3} \%$ & 19 & 12.5 & $6.3-34.7$ & 13 & 11.6 & $8.2-30.4$ & 6 & 20.0 & 6.3-34.7 & $>0.05$ \\
\hline $\mathrm{D}_{10}(\%)$ & 22 & 17.5 & 8.9-51.3 & 13 & 13.9 & $9.0-38.8$ & 9 & 28.1 & 8.9-51.3 & $<0.05$ \\
\hline $\mathrm{D}_{30}(\%)$ & 22 & 13.8 & $7.0-45.2$ & 13 & 10.7 & $7.0-32.1$ & 9 & 23.4 & $7.0-45.2$ & $<0.05$ \\
\hline $\mathrm{D}_{50}(\%)$ & 22 & 11.8 & $5.7-40.7$ & 13 & 8.9 & $5.7-27.4$ & 9 & 20.4 & $5.7-40.7$ & $<0.05$ \\
\hline $\mathrm{V}_{10}(\%)$ & 22 & 68.6 & $4.1-100.0$ & 13 & 36.3 & $4.7-100.0$ & 9 & 100.0 & 4.1-100.0 & $<0.05$ \\
\hline $\mathrm{V}_{30}(\%)$ & 22 & 0.0 & $0.0-97.9$ & 13 & 0.0 & $0.0-38.8$ & 9 & 5.2 & $0.0-97.9$ & $<0.05$ \\
\hline $\mathrm{V}_{50}(\%)$ & 22 & 0.0 & $0.0-13.2$ & 13 & 0.0 & 0.0-0.1 & 9 & 0.0 & 0.0-13.2 & $>0.05$ \\
\hline
\end{tabular}

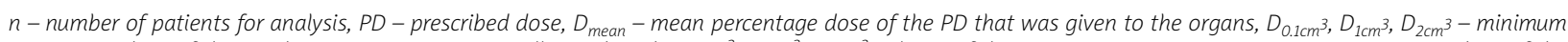
percentage dose of the $P D$ that was given to maximally irradiated $0.1 \mathrm{~cm}^{3}, 1 \mathrm{~cm}^{3}, 2 \mathrm{~cm}^{3}$ volume of the organs; $D_{10}, D_{30}, D_{50}-$ minimum percentage dose of the $P D$ that was given to $10 \%, 30 \%, 50 \%$ of the organs; $V_{10}, V_{30}, V_{50}$ - percentage volume of the organs receiving $10 \%, 30 \%, 50 \%$ or more of the $P D$

between mobile tongue (including floor of mouth) and base of tongue tumors.

\section{Dosimetric evaluation of critical structures}

\section{Mandible and spinal cord}

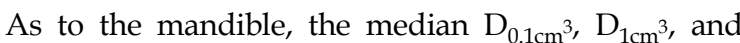
$\mathrm{D}_{2 \mathrm{~cm}}{ }^{3}$ were $81.8 \%$ (range, $25.1-134.1 \%$ ), $57.8 \%$ (range, 19.6 $81.6 \%$ ), and $48.3 \%$ (range, $17.5-73.2 \%$ ), respectively, whereas with regard to the spinal cord, corresponding values were $10.0 \%$ (range, $4.9-15.4 \%$ ), $6.8 \%$ (range, $3.3-11.8 \%$ ), and
5.8\% (range, 2.8-10.8\%) for all cases, respectively (Table 4). Comparing the 2 location groups (patients with base of tongue and patients with mobile tongue, including floor of mouth), the latter received significantly higher doses for the mandible (median $\mathrm{D}_{2 \mathrm{~cm}} 3: 50.3 \%$ vs. $36.2 \%$ ), while, on the other hand, significantly lower doses for the spinal cord (median $\mathrm{D}_{2 \mathrm{~cm}} 3: 5.3 \%$ vs. $7.0 \%$ ).

\section{Ipsilateral salivary glands}

Table 5 shows the evaluation of ipsilateral salivary glands related parameters. For all cases, the median $\mathrm{D}_{\text {mean }}$ 
Table 6. Evaluation of contralateral salivary glands-related parameters

\begin{tabular}{|c|c|c|c|c|c|c|c|c|c|c|}
\hline \multirow[t]{2}{*}{ Parameters } & \multicolumn{3}{|c|}{ All } & \multicolumn{3}{|c|}{$\begin{array}{l}\text { Mobile tongue, } \\
\text { floor of mouth }\end{array}$} & \multicolumn{3}{|c|}{ Base of tongue } & \multirow[t]{2}{*}{$p$ value } \\
\hline & $n$ & Median & Range & $n$ & Median & Range & $n$ & Median & Range & \\
\hline \multicolumn{11}{|l|}{ Parotid gland } \\
\hline $\mathrm{D}_{\text {mean }}(\%)$ & 15 & 3.1 & $1.1-4.1$ & 12 & 2.7 & $1.1-4.0$ & 3 & 4.0 & $2.6-4.1$ & $>0.05$ \\
\hline $\mathrm{D}_{0.1 \mathrm{~cm}^{3}}(\%)$ & 34 & 9.5 & $4.9-11.9$ & 21 & 9.6 & 4.9-11.9 & 13 & 9.5 & 6.8-11.2 & $>0.05$ \\
\hline $\mathrm{D}_{1 \mathrm{~cm}} \mathrm{~cm}^{3}(\%)$ & 34 & 6.0 & $3.3-8.8$ & 21 & 6.0 & $3.3-8.8$ & 13 & 5.9 & $3.5-7.8$ & $>0.05$ \\
\hline $\mathrm{D}_{2 \mathrm{~cm}} \mathrm{~cm}^{3}$ & 34 & 5.3 & 2.3-7.7 & 21 & 5.3 & $2.8-7.7$ & 13 & 5.2 & $2.3-6.9$ & $>0.05$ \\
\hline $\mathrm{D}_{10}(\%)$ & 15 & 5.7 & $2.5-6.7$ & 12 & 5.5 & $2.5-6.5$ & 3 & 6.6 & $5.5-6.7$ & $>0.05$ \\
\hline $\mathrm{D}_{30}(\%)$ & 15 & 4.0 & $1.7-5.1$ & 12 & 3.8 & $1.7-5.1$ & 3 & 5.0 & 3.8-5.1 & $>0.05$ \\
\hline $\mathrm{D}_{50}(\%)$ & 15 & 3.4 & $1.3-4.1$ & 12 & 3.1 & $1.3-4.0$ & 3 & 3.9 & $3.2-4.1$ & $>0.05$ \\
\hline $\mathrm{V}_{10}(\%)$ & 15 & 0.5 & $0.0-0.9$ & 12 & 0.4 & $0.0-0.8$ & 3 & 0.8 & $0.4-0.9$ & $>0.05$ \\
\hline \multicolumn{11}{|c|}{ Submandibular gland } \\
\hline $\mathrm{D}_{\text {mean }}(\%)$ & 33 & 6.8 & 2.9-29.3 & 20 & 5.8 & 2.9-11.2 & 13 & 9.9 & 4.4-29.3 & $<0.05$ \\
\hline $\mathrm{D}_{0.1 \mathrm{~cm}^{3}}(\%)$ & 33 & 11.7 & $5.8-34.5$ & 20 & 11.2 & 5.8-17.1 & 13 & 15.8 & 9.3-34.5 & $<0.05$ \\
\hline $\mathrm{D}_{1 \mathrm{~cm}^{3}}(\%)$ & 31 & 8.0 & $4.1-13.8$ & 20 & 7.7 & 4.1-13.5 & 11 & 11.2 & 5.8-13.8 & $>0.05$ \\
\hline $\mathrm{D}_{2 \mathrm{~cm}^{3}}(\%)$ & 31 & 7.0 & $3.6-12.4$ & 20 & 6.7 & $3.6-11.9$ & 11 & 9.5 & $4.6-12.4$ & $>0.05$ \\
\hline $\mathrm{D}_{10}(\%)$ & 33 & 9.6 & $4.2-35.1$ & 20 & 8.3 & $4.2-14.4$ & 13 & 13.3 & $7.0-35.1$ & $<0.05$ \\
\hline $\mathrm{D}_{30}(\%)$ & 33 & 7.7 & $3.4-31.5$ & 20 & 6.7 & $3.4-12.4$ & 13 & 11.2 & $5.3-31.5$ & $<0.05$ \\
\hline $\mathrm{D}_{50}(\%)$ & 33 & 6.8 & $2.8-29.0$ & 20 & 5.6 & 2.8-11.1 & 13 & 9.7 & 4.4-29.0 & $<0.05$ \\
\hline $\mathrm{V}_{10}(\%)$ & 33 & 6.0 & $0.0-100.0$ & 20 & 2.8 & $0.0-67.3$ & 13 & 45.1 & $1.0-100.0$ & $<0.05$ \\
\hline$V_{30}(\%)$ & 33 & 0.0 & $0.0-41.0$ & 20 & 0.0 & $0.0-0.0$ & 13 & 0.0 & $0.0-41.0$ & NA \\
\hline
\end{tabular}

$n$-number of patients for analysis, $P D$ - prescribed dose, Dmean - mean percentage dose of the $P D$ that was given to the organs, $D_{01} \mathrm{~cm}^{3}, D_{1 \mathrm{~cm}^{3}}, D_{2 \mathrm{~cm}}{ }^{3}-\mathrm{minim}_{\mathrm{imm}}$ percentage dose of the $P D$ that was given to maximally irradiated $0.1 \mathrm{~cm}^{3}, 1 \mathrm{~cm}^{3}, 2 \mathrm{~cm}$ volume of the organs; $D_{10}, D_{30}$, $D_{50}-$ minimum percentage dose of the $P D$ that was given to $10 \%, 30 \%, 50 \%$ of the organs; V10, V30, V50-percentage volume of the organs receiving $10 \%, 30 \%, 50 \%$ or more of the PD, NA - not available

Table 7. Correlation coefficient (R2) between parameters

\begin{tabular}{|c|c|c|c|c|c|c|c|}
\hline \multicolumn{2}{|c|}{ Target volume } & \multicolumn{6}{|c|}{ Critical structures } \\
\hline \multirow{2}{*}{$\begin{array}{l}\mathrm{V}_{100} \\
\text { and } \mathrm{D}_{90}\end{array}$} & \multirow{2}{*}{$\begin{array}{l}\text { VPTV } \\
\text { and } V_{100}\end{array}$} & \multicolumn{6}{|c|}{$\mathrm{D}_{1 \mathrm{~cm}^{3}}$ and $\mathrm{D}_{0.1 \mathrm{~cm}^{3}}$} \\
\hline & & Mandible & $\begin{array}{l}\text { Spinal } \\
\text { cord }\end{array}$ & $\begin{array}{l}\text { Ipsilateral } \\
\text { parotid gland }\end{array}$ & $\begin{array}{l}\text { Contralateral } \\
\text { parotid gland }\end{array}$ & $\begin{array}{c}\text { Ipsilateral } \\
\text { submandibular gland }\end{array}$ & $\begin{array}{c}\text { Contralateral } \\
\text { submandibular gland }\end{array}$ \\
\hline${ }^{*} 0.995$ & ${ }^{*} 0.960$ & 0.554 & *0.964 & ${ }^{*} 0.966$ & ${ }^{*} 0.940$ & ${ }^{*} 0.976$ & ${ }^{\star} 0.972$ \\
\hline
\end{tabular}

* - high correlation, PTV - planning target volume, PD - prescribed dose, $V_{100}$ - percentage volume of the PTV receiving $100 \%$ or more of the PD; $D_{90}-$ minimum percentage dose of the PD that was given to $90 \%$ of the PTV, VPTV - volume of the PTV, $V_{100}$-volume of the PTV receiving $100 \%$ or more of the PD; $D_{1 \mathrm{~cm}}{ }^{3}$, $D_{0.1 \mathrm{~cm}}{ }^{3}-$ minimum percentage dose of the PD that was given to maximally irradiated $1 \mathrm{~cm}^{3}, 0.1 \mathrm{~cm}^{3}$ volume of organs

$\mathrm{D}_{2 \mathrm{~cm}^{3}}, \mathrm{D}_{30}$ of parotid glands were $4.1 \%$ (range, $2.0-6.5 \%$ ), $6.4 \%$ (range, $3.8-11.8 \%$ ), and $5.1 \%$ (range, $2.6-7.6 \%$ ), whereas those of submandibular glands were $12.3 \%$ (range, 5.9-41.8\%), $12.5 \%$ (range, 6.3-34.7\%) and $13.8 \%$ (range, 7.0-45.2\%), respectively. The median percentage volume of parotid glands and submandibular glands receiving $10 \%$ or more of the $\mathrm{PD}\left(\mathrm{V}_{10}\right)$ were $0.8 \%$ (range, $0.0-9.1 \%$ ) and $68.6 \%$ (range, $4.1-100.0 \%$ ), respectively. Both $\mathrm{V}_{30}$ and $\mathrm{V}_{50}$ of parotid glands were $0.0 \%$ for each patient, whereas the median $\mathrm{V}_{30}$ and $\mathrm{V}_{50}$ of submandibular glands were $0.0 \%$ (range, $0.0-97.9 \%$ ) and $0.0 \%$ (range, $0.0-13.2 \%$ ), respectively. For parotid glands, there were no significant differences in the parameters between mobile tongue (including floor of mouth) and base of tongue cancer patients. On the other hand, for submandibular glands, 6 parameters $\left(\mathrm{D}_{\text {mean }}, \mathrm{D}_{10}, \mathrm{D}_{30}, \mathrm{D}_{50}, \mathrm{~V}_{10}\right.$, and $\left.\mathrm{V}_{30}\right)$ of base of tongue cancer patients were significantly higher than those of mobile tongue (including floor of mouth) cancer patients.

\section{Contralateral salivary glands}

Table 6 shows the evaluation of contralateral salivary glands related parameters. For all cases, the median $\mathrm{D}_{\text {mean }}, \mathrm{D}_{2 \mathrm{~cm}}{ }^{3}, \mathrm{D}_{30}$ of parotid glands were $3.1 \%$ (range, $1.1-4.1 \%$ ), $5.3 \%$ (range, 2.3-7.7\%), and $4.0 \%$ (range, 1.7$5.1 \%)$, whereas those of submandibular glands were $6.8 \%$ (range, $2.9-29.3 \%$ ), $7.0 \%$ (range, $3.6-12.4 \%$ ) and $7.7 \%$ (range, 3.4-31.5\%), respectively. The median percentage volume of parotid glands and submandibular glands receiving $10 \%$ or more of the PD $\left(\mathrm{V}_{10}\right)$ were $0.5 \%$ (range, $0.0-0.9 \%$ ) and $6.0 \%$ (range, $0.0-100.0 \%$ ), respectively. Both $\mathrm{V}_{30}$ and $\mathrm{V}_{50}$ of parotid glands were $0.0 \%$ for each patient, whereas the median $\mathrm{V}_{30}$ of submandibular glands was 

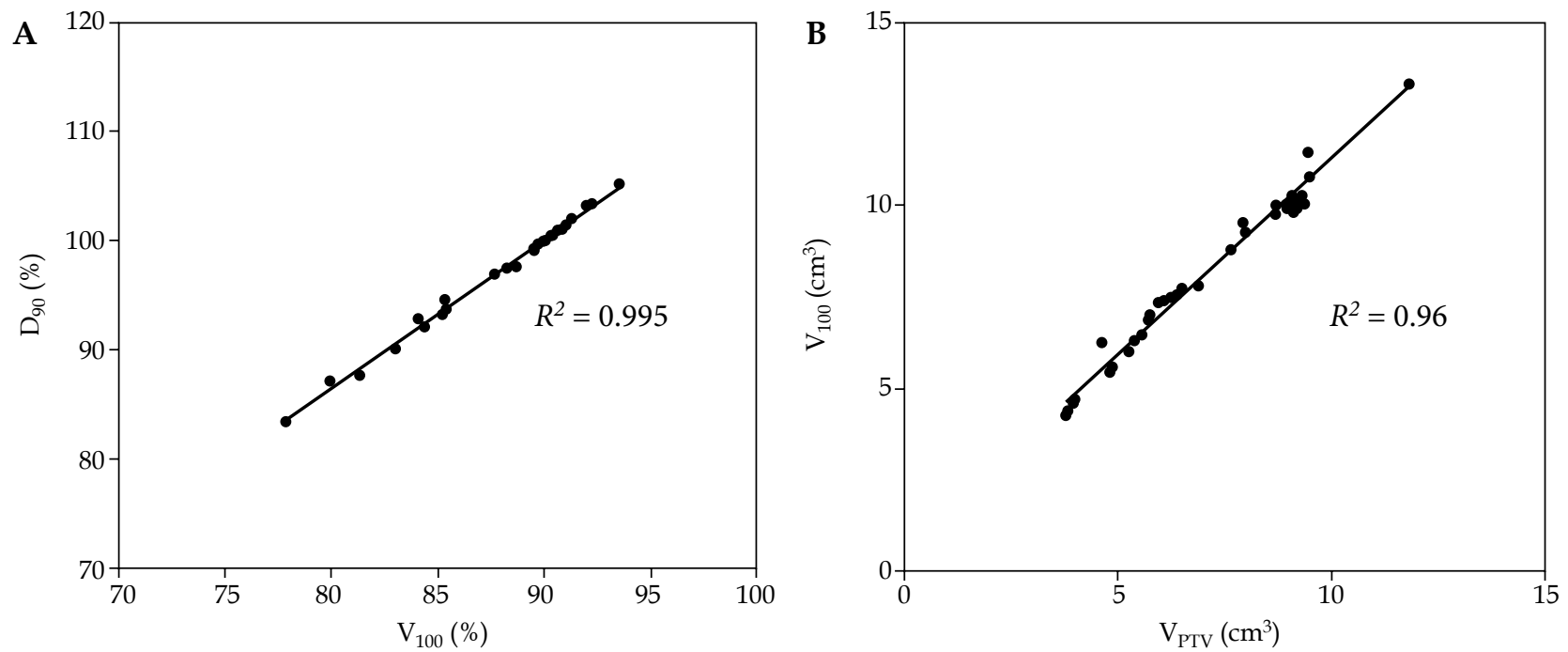

PTV - planning target volume, $P D$ - prescribed dose, $D_{90}(\%)$ - minimum percentage dose of the PD that was given to 90\% of the PTV, $V_{100}(\%)$ - percentage volume of the PTV receiving $100 \%$ or more of the PD, $V_{100}$-volume receiving $100 \%$ or more of the PD, $V_{P T V}$-volume of the PTV, $R^{2}-$ correlation coefficient

Fig. 1. Correlation between $D_{90}$ and $V_{100}(A)$, and $V_{100}$ and $V_{\text {PTV }}($ B)

$0.0 \%$ (range, $0.0-41.0 \%$ ) and $\mathrm{V}_{50}$ was $0.0 \%$ for each patient. For parotid glands, there were no significant differences in the parameters between mobile tongue (including floor of mouth) and base of tongue cancer patients. For submandibular glands, 6 parameters $\left(\mathrm{D}_{\text {mean }}, \mathrm{D}_{0.1 \mathrm{~cm}^{3}}, \mathrm{D}_{10}\right.$ $\mathrm{D}_{30}, \mathrm{D}_{50}$, and $\mathrm{V}_{10}$ ) of base of tongue cancer patients were significantly higher than those of mobile tongue (including floor of mouth) cancer patients.

\section{Correlation analysis}

The results are shown in Table 7. Good correlation was seen between $V_{100}$ and $D_{90}$, and $V_{\text {PTV }}$ and $V_{100}$ (Figure 1). $\mathrm{D}_{2 \mathrm{~cm}^{3}}$ correlated well with $\mathrm{D}_{1 \mathrm{~cm}^{3}}$ for all critical structures with $R^{2}>0.96 . \mathrm{D}_{1 \mathrm{~cm}}{ }^{3}$ also showed good correlation with $\mathrm{D}_{0.1 \mathrm{~cm}}{ }^{3}$ for all critical structures except for the mandible (Table 7).

\section{Discussion}

Development in BT planning makes it possible also in the head and neck region to evaluate dose-volume relationships concerning the target volume and critical structures. Compared with the conventional implant-based 2D treatment planning for mobile tongue cancer, 3D image-based BT planning may decrease irradiated doses to the mandible without compromising clinical target volume coverage [12]. At our institute, post-implantation CT image sets have been successfully used for HDR head and neck BT. For high quality image-based BT, 3D tomographic image sets of target and critical structures are highly recommended. Therefore, the dose plan evaluation for implant, PTV, and critical structures using DVH data have great significance. Although the software we applied in this study did not take into account the exact patient dimension and tissue heterogeneities, our results are not affected by the small inaccuracies in dose calculation [17]. In this study, we did not consider the indications of HDR BT, only the dosimetric analysis of interstitial therapy. Previously, there were only a few data available about the exact dose prescription of HDR BT, so fractionation schedule of our study was inhomogeneous.

\section{Implant related parameters}

There is no agreement on what degree of dose non-uniformity is permitted in the image-based head and neck HDR BT. Systematic collection and documentation of implant quality measures (COIN, DNR, etc.) for future evaluation are advisable [16]. Strnad et al. [16] reported that DNR should be equal to or lower than 0.36 and in IMBT (intensity modulated brachytherapy), this value should be 0.42 . Guinot et al. [18] did not allow a hot spot joining two tubes in order to keep DNR under 0.35. In small gross tumor volumes (few $\mathrm{cm}^{3}$ and applicator spacing is less than $10 \mathrm{~mm}$ ), the DNR may be as high as 0.50-0.52 [15]. For all our patients, the median DNR was 0.46 . Our results are slightly worse compared with the literature data. However, more dosimetric studies would be needed because there is no clear consensus for the acceptable value of DNR. It is to be noted that the DNR can depend considerably on the number of catheters. The higher their number, the better the DNR, but on the other hand, great number of catheters can cause inconvenience to the patients.

\section{PTV related parameters}

According to the GEC-ESTRO recommendation, the prescription dose is usually the minimum dose delivered to the clinical target volume (CTV) or a CTV surrogate (i.e., the $\mathrm{D}_{90}>100, \mathrm{~V}_{100}>90 \%$ ) [15]. Evaluating 74 patients, in the study of Tselis et al. [19], the median $\mathrm{V}_{100}$, $\mathrm{V}_{150}$, and $\mathrm{D}_{90}$ were $88.8 \%, 58.0 \%$, and $97.7 \%$, respectively. In another study by Yoshida et al. [12], the mean $\mathrm{V}_{100}$, $\mathrm{D}_{90}$, and $\mathrm{D}_{100}$ were $98.1 \%, 112.4 \%$, and $86.7 \%$, respectively. In the current study, for all patients, the median $\mathrm{V}_{100}, \mathrm{~V}_{150}, \mathrm{D}_{90}$, and $\mathrm{D}_{100}$ were $89.9 \%, 44.1 \%, 99.9 \%$, and $57.0 \%$, respectively. These results are very proximal to the GEC-ESTRO's recommendations. Our results of $D_{100}$ 
are low, presumably because of the irregular shape of the PTV. $D_{90}$ has shown a good correlation with $V_{100}$, and this means that independently of the shape of the PTV, $\mathrm{D}_{90}$ is a good parameter to evaluate the target coverage. The volume of the PTV ( $\mathrm{V}_{\text {PTV }}$ ) has shown a good correlation with the irradiated volume of $100 \% \mathrm{PD}\left(\mathrm{V}_{100}\right)$. The reason for this is that in most cases, the coverage $\left(\mathrm{V}_{100}\right)$ was close to $90 \%$. Cisek et al. [7] calculated DHI for 4 patients of oropharyngeal, lip, larynx, and maxillary cancer. Their median DHI was 0.31 and in our study, it was 0.50. As regards to conformity, internationally accepted recommendations are not available. Upreti et al. [11] found a mean COIN value of 0.52 ; in our study, we demonstrated 0.64 for all patients. Our somewhat higher value means smaller normal tissue irradiated by the PD.

\section{Critical structures related parameters}

No specific tolerance doses to critical structures are given in the GEC-ESTRO recommendations. They only prescribe to keep the doses to organs at risk as low as possible [15].

\section{Mandible and spinal cord}

In an early study, Yoshida et al. [12] evaluated 5 mobile tongue cancer patients treated by image-based HDR BT (CT and MRI used). They indicated that the mean $\mathrm{D}_{0.1 \mathrm{~cm}^{3}}, \mathrm{D}_{1 \mathrm{~cm}} 3$, and $\mathrm{D}_{2 \mathrm{~cm}^{3}}$ of the mandible were $80.1 \%$, $62.5 \%$, and $55.7 \%$, respectively. In our study for mobile tongue (including floor of mouth) cancer patients, the median $\mathrm{D}_{0.1 \mathrm{~cm}^{3}}, \mathrm{D}_{1 \mathrm{~cm}^{3}}$, and $\mathrm{D}_{2 \mathrm{~cm}^{3}}$ were $84.1 \%, 58.6 \%$, and $50.3 \%$, respectively. From these results, the acceptable level of $D_{0.1 \mathrm{~cm}^{3}}, \mathrm{D}_{1 \mathrm{~cm}^{3}}$, and $\mathrm{D}_{2 \mathrm{~cm}^{3}}$ of the mandible for mobile tongue cancer may be roughly $80 \%, 60 \%$, and $55 \%$, respectively. For the mandible, high correlation was found between $D_{2 \mathrm{~cm}^{3}}$ and $D_{1 \mathrm{~cm}^{3}}$, whereas no correlation was found between $D_{1 \mathrm{~cm}^{3}}$ and $D_{0.1 \mathrm{~cm}^{3}}$ (Table 7). The explanation for this latter observation is that $\mathrm{D}_{0.1 \mathrm{~cm}^{3}}$ parameter is very sensitive to the distance between the mandible and the PTV. If the PTV is close to the mandible, the $100 \%$ isodose line can cover a small volume $\left(\mathrm{D}_{0.1 \mathrm{~cm}^{3}}\right)$ of the mandible, but if the PTV is far from it, the $100 \%$ isodose line does not reach the mandible. However, volumes irradiated by lower doses are not influenced significantly by the distance. That is the reason for good correlation between $D_{1 \mathrm{~cm}^{3}}$ and $D_{2 \mathrm{~cm}^{3}}$. Therefore, it is necessary to report $D_{2 \mathrm{~cm}^{3}}, \mathrm{D}_{1 \mathrm{~cm}^{3}}$, and $\mathrm{D}_{0.1 \mathrm{~cm}^{3}}$ parameters and the relationships between these data and late complications of the mandible. No former investigation has been found in the literature about minimum percentage dose of the PD received by the maximally irradiated small volumes for the spinal cord.

\section{Salivary glands}

In our study, the doses delivered to the ipsilateral or contralateral salivary glands with respect to each primary site are compared to the results of an early study. Bhalavat et al. [6] estimated the doses for mobile tongue and base of tongue implantations. For ipsilateral parotid glands (our results are in parenthesis), they found that the mean $\mathrm{D}_{\text {mean }}$ and $\mathrm{D}_{30}$ were $5.7 \%(3.7 \%)$ and $6.5 \%(4.8 \%)$ for mobile tongue lesion, and 8.6\% (5.8\%) and 9\% (6.9\%) for base of tongue lesion, and for ipsilateral submandibular glands those were $18.4 \%(9.4 \%)$ and $17 \%(10.7 \%)$ for mobile tongue lesion, and $45.9 \%(21.0 \%)$ and $48.9 \%$ (23.4\%) for base of tongue lesion, respectively. For contralateral parotid glands, the mean $\mathrm{D}_{\text {mean }}$ and $\mathrm{D}_{30}$ were $2.3 \%(2.7 \%)$ and $4.4 \%(3.8 \%)$ for mobile tongue lesion and $5.7 \%(4.0 \%)$ and $8.1 \%(5.0 \%)$ for base of tongue lesion, and for contralateral submandibular glands those were $11.1 \%$ $(5.8 \%)$ and $9.3 \%(6.7 \%)$ for mobile tongue lesion, and $23.6 \%(9.9 \%)$ and $26.5 \%$ (11.2\%) for base of tongue lesion, respectively. An almost identical dosimetric pattern was observed between these two studies, emphasizing that the doses received by the ipsilateral submandibular glands were about twice as large as the doses received by the contralateral submandibular glands. In our study, almost all values were lower than in the above-mentioned study. We think that one reason for this observation may be our smaller implant volumes compared to theirs $\left(16 \mathrm{~cm}^{3}\right.$ vs. $33 \mathrm{~cm}^{3}$ for mobile tongue lesion).

\section{Conclusions}

This study presented dosimetric characteristics for target volume and critical structures in CT image-based multicatheter HDR interstitial BT for head and neck cancer. By conformal treatment planning, it was possible to maintain the dose to the mandible at an acceptable level, while the doses to the spinal cord and contralateral salivary glands were generally low. The quantitative plan evaluation may help us find correlations between dosimetric parameters and clinical outcome, and may lead to improve the quality of the treatment, but it requires longer follow-up and results from other studies.

\section{Disclosure}

Authors report no conflict of interest.

\section{References}

1. Mazeron JJ, Ardiet JM, Haie-Méder C et al. GEC-ESTRO recommendations for brachytherapy for head and neck squamous cell carcinomas. Radiother Oncol 2009; 91: 150-156.

2. Erickson BA, Demanes DJ, Ibbott GS et al. American Society for Radiation Oncology (ASTRO) and American College of Radiology (ACR) practice guideline for the performance of high-dose-rate brachytherapy. Int J Radiat Oncol Biol Phys 2011; 79: 641-649.

3. Takácsi-Nagy Z, Martínez-Mongue R, Mazeron JJ et al. American Brachytherapy Society Task Group Report: Combined external beam irradiation and interstitial brachytherapy for base of tongue tumors and other head and neck sites in the era of new technologies. Brachytherapy 2017; 16: 44-58.

4. Yamazaki H, Yoshida K, Yoshioka Y et al. High dose rate brachytherapy for oral cancer. J Radiat Res 2013; 54: 1-17.

5. Bhalavat R, Chandra M, Pareek V et al. High-dose-rate interstitial brachytherapy in head and neck cancer: do we need a look back into a forgotten art-a single institute experience. J Contemp Brachytherapy 2017; 9: 124-131.

6. Bhalavat RL, Vyas S, Jamema SV et al. Quantitative estimation of doses to salivary glands from using brachytherapy in head and neck cancers. Brachytherapy 2011; 10: 81-86. 
7. Cisek P, Kieszko D, Brzozowska A et al. Image-guided highdose-rate brachytherapy of head and neck - a case series study. J Contemp Brachytherapy 2016; 8: 544-553.

8. Major T, Polgar C, Mangel L et al. CT based conformal brachytherapy treatment planning. Magyar Onkologia 2000; 44: 109-115 [Article in Hungarian].

9. Mukherji A, Mourougan S, Saravannan K et al. Dosimetric analysis and clinical outcomes in CT-based mould brachytherapy in early oral cancers in patients unfit for surgery. J Contemp Brachytherapy 2015; 7: 147-153.

10. Tselis N, Karagiannis E, Kolotas C et al. Image-guided interstitial high-dose-rate brachytherapy in the treatment of inoperable recurrent head and neck malignancies: An effective option of reirradiation. Head Neck 2017; 39: E61-E68.

11. Upreti RR, Dayananda S, Bhalawat RL et al. Evaluation of radiograph-based interstitial implant dosimetry on computed tomography images using dose volume indices for head and neck cancer. J Med Phys 2007; 32: 60-64.

12. Yoshida $\mathrm{K}$, Takenaka $\mathrm{T}$, Akiyama $\mathrm{H}$ et al. Three-dimensional image-based high-dose-rate interstitial brachytherapy for mobile tongue cancer. J Radiat Res 2014; 55: 154-161.

13. Pötter R, Haie-Meder C, van Limbergen $E$ et al. Recommendations from Gynaecological (GYN) GEC ESTRO Working Group (II): concepts and terms in 3D image-based treatment planning in cervix cancer brachytherapy-3D dose volume parameters and aspects of 3D image-based anatomy, radiation physics, radiobiology. Radiother Oncol 2006; 78: 67-77.

14. Haie-Meder C, Pötter R, Van Limbergen E et al. Recommendations from Gynaecological (GYN) GEC-ESTRO Working Group (I): concepts and terms in 3D image based 3D treatment planning in cervix cancer brachytherapy with emphasis on MRI assessment of GTV and CTV. Radiother Oncol 2005; 74: 235-245.

15. Kovács G, Martinez-Monge R, Budrukkar A et al. GEC-ESTRO ACROP recommendations for head \& neck brachytherapy in squamous cell carcinomas: $1^{\text {st }}$ update - Improvement by cross sectional imaging based treatment planning and stepping source technology. Radiother Oncol 2017; 122: 248-254.

16. Strnad V, Pötter R, Kovács G. Practical handbook of brachytherapy. UNI-MED Verlag, Bremen-London-Boston 2014; 166183.

17. Peppa V, Pappas E, Major T et al. On the impact of improved dosimetric accuracy on head and neck high dose rate brachytherapy. Radiother Oncol 2016; 120: 92-97.

18. Guinot JL, Santos M, Tortajada MI et al. Efficacy of highdose-rate interstitial brachytherapy in patients with oral tongue carcinoma. Brachytherapy 2010; 9: 227-234.

19. Tselis N, Ratka M, Vogt HG et al. Hypofractionated accelerated CT-guided interstitial ${ }^{192}$ Ir-HDR-Brachytherapy as re-irradiation in inoperable recurrent cervical lymphadenopathy from head and neck cancer. Radiother Oncol 2011; 98: 57-62. 